\title{
Failure of early postnatal dexamethasone to prevent chronic lung disease in infants with respiratory distress syndrome
}

Soroka Medical Center, Beersheva E S Shinwell M Karplus

E Zmora

Ha'emek Medical Center, Afula D Reich

Carmel Medical Center, Haifa A Rothschild

Rambam Medical Center, Haifa $S$ Blazer

Bnei-Zion Medical Center, Haifa D Bader

Hillel Yaffe Medical Center, Hadera $S$ Yurman

Meir Medical Center, Kfar Saba

T Dolfin

Sheba Medical Center, Tel Hashomer

J Kuint

Hakirya Medical Center, Tel Aviv

B Milbauer

Wolfson Medical Center, Holon

D Kohelet

Assaf Harofe Medical Center, Tsrifin M Goldberg

Bikur Holim Medical Center, Jerusalem Y Armon

Beilinson Medical Center, Petach Tikva $S$ Davidson

Hasharon Medica Center, Petach Tikva L Sirota

Kaplan Medical

Center, Rechovot

M Amitai

Barzilai Medical Center, Ashkelon A Zaretsky

Nahariya Regional Medical Center

M Barak

Rivka Ziv Medical Center, Tsfat

$S$ Gottfried

Correspondence to: Eric S Shinwell, Department of Neonatology, Soroka of Neonatology, Soroka Medica

Israel.

Accepted 29 September 1995

E S Shinwell, M Karplus, E Zmora, D Reich, A Rothschild, S Blazer, D Bader, $S$ Yurman, T Dolfin, J Kuint, B Milbauer, D Kohelet, M Goldberg, Y Armon, $S$ Davidson, L Sirota, M Amitai, A Zaretsky, M Barak, S Gottfried

\begin{abstract}
Objective-To study the effect of early postnatal dexamethasone (days 1-3) on the incidence and severity of chronic lung disease in preterm infants with respiratory distress syndrome.
\end{abstract}

Methods-A multicentre, randomised, placebo controlled, blinded study was carried out in 18 neonatal intensive care units in Israel. The primary outcome measure was survival to discharge without requirement for supplemental oxygen therapy beyond 28 days of life. The secondary outcome measures were requirement for mechanical ventilation at 3 and 7 days, duration of ventilation or oxygen therapy, need for subsequent steroids for established chronic lung disease and incidence of major morbidities.

Results-The study consisted of 248 infants (dexamethasone $n=132$; placebo $n=116)$. No differences were found in the outcome variables except for a reduction in requirement for mechanical ventilation at age 3 days in treated infants (dexamethasone $44 \%$, placebo $67 \%$; $P=0.001$ ). Gastrointestinal haemorrhage, hypertension, and hyperglycaemia were more common in treated infants, but no life threatening complications, such as gastrointestinal perforation, were encountered. Conclusions-These data do no support the routine use of early postnatal steroids, but may justify further study in a selected, high risk group of infants.

(Arch Dis Child 1996; 74: F33-F37)

Keywords: respiratory distress syndrome, steroids, surfactant, chronic lung disease.

The incidence of chronic lung disease (CLD) in premature infants remains distressingly high in spite of the reduction in acute morbidity and mortality resulting from the recent introduction of surfactant treatment for respiratory distress syndrome (RDS). ${ }^{1-3}$ Steroid treatment has been shown to be effective in ameliorating established CLD, presumably mainly by its anti-inflammatory actions. ${ }^{4-7}$ Cellular and biochemical studies have shown inflammatory changes in the lungs of ventilated infants as early as the first few days of life, ${ }^{8-10}$ and dexamethasone has been shown to reduce this inflammation. ${ }^{11} 12$ Thus it has been postulated that steroid treatment administered shortly after birth may prevent the inflammatory insult to the lung and thereby reduce the likelihood of CLD. ${ }^{13}$ Early steroid treatment may also increase the postnatal induction of surfactant synthesis and secretion. Five randomised controlled trials of early postnatal steroid treatment have been reported, with mixed results. ${ }^{13-17}$ Three of these studies were conducted before the routine availability of surfactant therapy and they all had relatively small study populations. Three of the studies used a long course of treatment of 12-28 days, which was felt by this group of investigators possibly to incur a significant risk of steroid related adverse events. The two other studies used an extremely short course of treatment (2 doses) which may possibly have been inadequate.

Thus we report a multicentre, randomised, blinded, placebo-controlled trial of a three day, early postnatal course of dexamethasone treatment in preterm infants with respiratory distress syndrome, who were treated with surfactant.

\section{Methods}

The study protocol was approved by the Human Investigation Committee of each participating centre and also by the Ministry of Health of Israel. Informed parental consent was obtained for each infant.

All infants meeting criteria were considered for inclusion in the study. The inclusion criteria were: clinical and radiographic diagnosis of RDS; requiring mechanical ventilation and $\mathrm{FIO}_{2}>0.4$ with a $\mathrm{PaO}_{2}$ of $50-80 \mathrm{~mm} \mathrm{Hg}$; birthweight $500-2000 \mathrm{~g}$; less than 12 hours of age; no contraindications to steroids, such as bleeding tendency, hypertension, hyperglycaemia or active infection; and no lethal congenital malformation.

The primary outcome measure was survival to discharge without requirement for supplemental oxygen beyond 28 days of life. The secondary outcome measures were the requirement for mechanical ventilation or oxygen at the end of the study drug course - three days and before subsequent steroid treatment for established CLD was permitted after 7 days of age. Additional measures of outcome included oxygen requirement at 36 and 40 weeks, corrected gestational age, duration of mechanical ventilation or oxygen treatment, requirement for subsequent steroids for established CLD, and the incidence of major associated morbidity. The minimum study sample size was 
Table 1 Baseline characteristics of the infants in both study groups (continuous variables are expressed as mean (SEM))

\begin{tabular}{lcc}
\hline & $\begin{array}{l}\text { Dexamethasone } \\
(n=132)\end{array}$ & $\begin{array}{l}\text { Placebo } \\
(n=116)\end{array}$ \\
\hline Birthweight (g) & $1185(35)$ & $1174(34)$ \\
Gestational age (weeks) & $29(0 \cdot 2)$ & $29(0 \cdot 2)$ \\
Sex $(M / F)$ & $76 / 56$ & $66 / 49$ \\
ROM $>24$ hours & $13(10)$ & $14(12)$ \\
Apgar at 5 minutes & $7 \cdot 5(0 \cdot 2)$ & $7 \cdot 8(0 \cdot 2)$ \\
Caesarean section delivery & $77(58)$ & $70(60)$ \\
Singleton birth & $98(74)$ & $83(72)$ \\
Inborn & $129(99)$ & $115(99)$ \\
Antenatal steroids & $97(73)$ & $86(74)$ \\
None & $13(10)$ & $11(9)$ \\
Partial & $21(16)$ & $19(16)$ \\
Complete & & \\
\hline
\end{tabular}

Discrete variables are expressed as the $\mathrm{n}$ with $\%$ in parentheses. ROM= rupture of membranes.

Table 2 Severity of initial disease

\begin{tabular}{lcc}
\hline & $\begin{array}{c}\text { Dexamethasone } \\
(n=132)\end{array}$ & $\begin{array}{c}\text { Placebo } \\
(n=116)\end{array}$ \\
\hline First 12 hours of life & $0 \cdot 85(0 \cdot 2)$ & $0 \cdot 82(0 \cdot 2)$ \\
Highest FIO & & \\
Lowest pH & $7 \cdot 22(0 \cdot 01)$ & $7 \cdot 22(0 \cdot 01)$ \\
Lowest MABP (mm Hg) & $31(0 \cdot 7)$ & $29(0 \cdot 6)$ \\
Age at MV (hour) & $1 \cdot 2(0 \cdot 3)$ & $1 \cdot 5(0 \cdot 4)$ \\
Age at first surfactant (hour) & $4 \cdot 4(0 \cdot 4)$ & $4 \cdot 8(0 \cdot 4)$ \\
$x$ Ray grade & $2 \cdot 9(0 \cdot 1)$ & $2 \cdot 8(0 \cdot 1)$ \\
Settings before study drug & & \\
a:A Po & $0 \cdot 15(0 \cdot 01)$ & $0 \cdot 15(0 \cdot 01)$ \\
MAP (cm $\left.\mathrm{H}_{2} \mathrm{O}\right)$ & $8 \cdot 9(0 \cdot 2)$ & $8 \cdot 4(0 \cdot 2)$ \\
Oxygenation index & $12(0 \cdot 8)$ & $12 \cdot 8(0 \cdot 8)$ \\
& &
\end{tabular}

$\mathrm{MV}=$ mechanical ventilation; $\mathrm{MABP}=$ mean arterial blood pressure; a: $\mathrm{A} \mathrm{Po}_{2}=$ arterial:alveolar oxygenation ratio; $\mathrm{MAP}=$ mean airway pressure.

calculated assuming $5 \%$ error and a power of $80 \%$, therefore estimating that it would be possible to detect an increase from $50 \%$ to $70 \%$ in the primary outcome variable with a sample size of 206 infants (103 pairs).

Eighteen centres participated in the study with four to 50 infants per centre. (In view of the small number of infants enrolled from some centres, no analysis of the effect of centre allocation was performed.) Each participating unit was supplied with numbered sets of syringes containing either dexamethasone $1 \mathrm{mg}$ in $0.25 \mathrm{ml}$ or physiological saline. The syringes were prepared with full sterile technique under a laminar flow hood by the study pharmacist in the Pharmacy Department at Soroka Medical Center, Beersheva. Following preparation, each syringe was stored in a sealed, nylon sleeve. Syringes containing dexamethasone were not distinguishable from those containing saline. Syringe sets were numbered according to a random number list. Randomisation was stratified by centre and by two birthweight groups - 500-1000 g and 1001-2000 $\mathrm{g}$ - to prevent chance sampling inequality. The drug assignment was not

Table 3 Primary and secondary outcome variable

\begin{tabular}{llll}
\hline & $\begin{array}{l}\text { Dexamethasone } \\
(n=132)\end{array}$ & $\begin{array}{l}\text { Placebo } \\
(n=116)\end{array}$ & $\begin{array}{l}\text { Odds ratio } \\
(95 \% C I)\end{array}$ \\
\hline $\begin{array}{l}\text { Primary outcome } \\
\text { Survival, no } \mathrm{O}_{2}>28 \mathrm{~d}\end{array}$ & $72(55)$ & $71(61)$ & $0 \cdot 76(0 \cdot 46,1 \cdot 26)$ \\
$\begin{array}{l}\text { Survival, } \mathrm{O}_{2}>28 \mathrm{~d} \\
\text { Died }\end{array}$ & $29(22)$ & $23(20)$ & $1 \cdot 14(0 \cdot 62,2 \cdot 1)$ \\
$\begin{array}{l}\text { Secondary outcome needing } M V \\
\text { 3 Days }\end{array}$ & $31(24)$ & $22(19)$ & $1 \cdot 31(0 \cdot 71,2 \cdot 4)$ \\
7 Days & $54 / 122(44)$ & $71 / 106(67)^{\star}$ & $0 \cdot 4(0 \cdot 24,0 \cdot 68)^{\star}$ \\
& $27 / 113(24)$ & $34 / 100(34)$ & $0 \cdot 61(0 \cdot 34,1 \cdot 11)$
\end{tabular}

Denominators at 3 and 7 days represent number of survivors at each age. ${ }^{\star} P=0 \cdot 001$. known to any of the investigators until after the three month observation period of the last enrolled infant. When an infant who met inclusion criteria was identified, the local investigator telephoned the central randomisation unit in the Department of Neonatology at Soroka Medical Center, Beersheva, and a study number was assigned corresponding to the syringe set to be administered. The syringe set was opened and $0.75 \mathrm{ml}$ saline was added to achieve a final concentration of $1 \mathrm{mg} / \mathrm{ml}$ of dexamethasone (or its placebo equivalent). The dosage regimen was $0.25 \mathrm{mg} / \mathrm{kg}$ intravenously, every 12 hours for a total of six doses. Subsequent steroid treatment for established CLD was permitted after 1 week of age. Otherwise, routine clinical care was at the discretion of the attending neonatologist.

Bovine surfactant (Surfactant TA, Surfacten) was supplied by Tokyo Tanabe, Japan and administered to all infants as a rescue treatment according to the manufacturer's guidelines. Each dose of surfactant was $100 \mathrm{mg} / \mathrm{kg}(30 \mathrm{mg} / \mathrm{ml})$ and up to 4 doses per infant were permitted.

Data collection included: baseline patient characteristics (birthweight, gestational age, sex, multiplicity); obstetric data (inborn/ outborn, antenatal steroids, rupture of membranes, delivery type, Apgar score); severity of initial disease (age at mechanical ventilation and age at surfactant treatment, chest $x$-ray grade, ${ }^{18}$ highest $\mathrm{FIO}_{2}$, lowest $\mathrm{pH}$ and lowest mean arterial blood pressure in the first 12 hours of life); ventilatory and oxygen requirements and arterial blood gasses before and after surfactant and at age 24 hours and age 3 and 7 days; number of doses of surfactant and study drug received and, if the full six doses of study drug were not administered, the reason for discontinuation; adverse events attributed by the attending neonatologist to dexamethasone, such as hypertension, hyperglycaemia, infection, gastrointestinal haemorrhage, etc; outcome in terms of mortality and associated major morbidity, such as CLD and the need for subsequent steroid treatment, intraventricular haemorrhage, periventricular leucomalacia, retinopathy of prematurity, patent ductus arteriosus, pulmonary air leak, pulmonary haemorrhage, sepsis, pneumonia, necrotising enterocolitis, apnoea and seizures.

Completed data sheets were sent to the Data Coordinating Unit for double data entry computerisation on the spreadsheet package Quattro Pro for Windows. The range of acceptable values for each data field was predefined and discrepancies were rechecked at source.

Cranial ultrasound scans were performed at 1 and 6 weeks of age and were assessed for the presence of localised, intraventricular or parenchymal haemorrhage, ventricular dilatation, and parenchymal cysts. ${ }^{19}$ Retinopathy of prematurity was defined according to the standard international classification. ${ }^{20}$ Patent ductus arteriosus was diagnosed by standard clinical, radiographic, and echocardiographic criteria.

Statistical analysis was performed using the SPSS for Windows software package. 
Table 4 Markers of chronic lung disease (CLD)

\begin{tabular}{lcc}
\hline & $\begin{array}{c}\text { Dexamethasone } \\
(n=132)\end{array}$ & $\begin{array}{l}\text { Placebo } \\
(n=116)\end{array}$ \\
\hline Days $\mathrm{MV}$ & $9(1 \cdot 2)$ & $11(1)$ \\
Days in $\mathrm{O}_{2}$ & $20(3)$ & $19(3)$ \\
Days in $>40 \% \mathrm{O}_{2}$ & $8(1)$ & $10(4)$ \\
$\mathrm{O}_{2}$ at 28 days & $32(24)$ & $24(21)$ \\
$\mathrm{O}_{2}$ at 36 weeks & $15(11)$ & $11(9)$ \\
$\mathrm{O}_{2}$ at 40 weeks & $6(5)$ & $6(5)$ \\
Steroids for CLD & $24(27)$ & $30(26)$ \\
Days of steroids for CLD & $3(1)$ & $6(1)$ \\
Duration of hospital stay (days) & & \\
Survivors & $63(3)$ & $65(4)$ \\
Died & $12(3)$ & $10(4)$ \\
\hline
\end{tabular}

Student's $t$ test was used for comparison of means of continuous variables. For variables with marked skewness of distribution, the Mann-Whitney U-Wilcoxon Rank Sum Test was used. $\chi^{2}$ or Fisher's exact test was used for categorical variables and odds ratios and $95 \%$ confidence intervals were also calculated. A P value of less than 0.05 was considered significant. All comparisons were made between the complete treated and placebo groups.

\section{Results \\ BASELINE CHARACTERISTICS AND INITIAL SEVERITY OF DISEASE}

During the study period, April 1993 to January 1994,255 infants were enrolled in the study. Seven infants were subsequently excluded from analysis. Three infants had major congenital abnormalities (two myotonic dystrophy and one cyanotic congenital heart disease) which had not been diagnosed at the time of randomisation. Three infants had errors in drug administration and one was randomised beyond 12 hours of age. Thus the final study sample consisted of 248 infants, of whom 132 received dexamethasone and 116 received placebo. In the 500-1000 g group there were 108 infants, with 59 receiving dexamethasone and 49 placebo. Of the 140 infants in the 1001-2000 g group, 73 received dexamethasone and 67 placebo. Table 1 shows the

Table 5 Major morbidity

\begin{tabular}{|c|c|c|c|}
\hline & $\begin{array}{l}\text { Dexamethasone } \\
(n=132)\end{array}$ & $\begin{array}{l}\text { Placebo } \\
(n=116)\end{array}$ & $\begin{array}{l}\text { Odds ratio } \\
(95 \% C I)\end{array}$ \\
\hline $\begin{array}{l}\text { Intraventricular haemorrhage grade II+ } \\
\text { Ventricular dilatation } \\
\text { Periventricular leucomalacia } \\
\text { ROP (grade 3+) } \\
\text { Pneumothorax } \\
\text { PIE } \\
\text { PDA } \\
\text { NEC } \\
\text { Sepsis }\end{array}$ & $\begin{array}{l}7 / 88(8) \\
7 / 88(8) \\
16 / 88(18) \\
10(8) \\
9(7) \\
6(5) \\
25(19) \\
10(8) \\
32(24)\end{array}$ & $\begin{array}{l}10 / 76(13) \\
6 / 76(8) \\
9 / 76(12) \\
8(7) \\
13(11) \\
6(5) \\
32(28) \\
10(10) \\
37(32)\end{array}$ & $\begin{array}{l}0.57(0.21,1.56) \\
1.01(0.32,3.13) \\
1.63(0.7,3.82) \\
1.11(0.42,2 \cdot 89) \\
0.58(0.24,1.4) \\
0.87(0.27,2.79) \\
0.61(0.34,1.11) \\
0.87(0.35,2.17) \\
0.68(0.39,1.19)\end{array}$ \\
\hline
\end{tabular}

$\mathrm{ROP}=$ retinopathy of prematurity; $\mathrm{PIE}=$ pulmonary interstitial emphysema; $\mathrm{PDA}=$ patent ductus arteriosus; NEC =necrotising enterocolitis. Ventricular dilatation refers to hydrocephalus $>4$ $\mathrm{mm}$ above the 97 th percentile. Denominators in IVH, ventricular dilatation, and PVL refer to number of available ultrasound examinations.

Table 6 Complications attributed to study drug by local investigator

\begin{tabular}{lccl}
\hline & $\begin{array}{c}\text { Dexamethasone } \\
(n=132)\end{array}$ & $\begin{array}{c}\text { Placebo } \\
(n=116)\end{array}$ & $\begin{array}{l}\text { Odds ratio } \\
(95 \% \text { CI })\end{array}$ \\
\hline Hypertension & $8(6)$ & $2(2)$ & $3 \cdot 05(0 \cdot 86,10 \cdot 82)$ \\
Hyperglycaemia & $16(12)$ & $9(8)$ & $1.62(0 \cdot 71,3 \cdot 69)$ \\
Sepsis & $4(3)$ & $8(7)$ & $0 \cdot 43(0 \cdot 14,1 \cdot 38)$ \\
Gastrointestinal haemorrhage & $28(21)$ & $12(10)$ & $2 \cdot 23(1 \cdot 13,4 \cdot 38)$ \\
Less than 6 doses of drug/placebo course & $17(13)$ & $6(5)$ & $2 \cdot 49(1 \cdot 06,5 \cdot 87)$ \\
\hline
\end{tabular}

baseline characteristics of the groups. No significant differences were noted. In particular, the incidence of antenatal steroid use was low, overall, and no difference was found between the study groups.

Severity of disease before the study intervention was analysed. Table 2 shows that there were no significant differences between the treated and placebo infants.

\section{OUTCOME}

No differences were found between the treated and placebo groups in survival without chronic lung disease - that is, the primary outcome variable (table 3).

Significantly fewer of the treated infants required ventilation at the completion of steroid treatment at age 3 days than placebo infants (dexamethasone $44 \%$, placebo $67 \%$, $\mathbf{P}=0.001)$. However, at 7 days of age, this difference was much less noticeable and no longer met statistical significance.

\section{RESPONSE TO SURFACTANT}

Surfactant administration was followed by a substantial and rapid improvement in oxygenation with the a:A ratio rising by $233(46 \%)$ from before $(0.14(0.12))$ to one hour after administration $(0.33(0 \cdot 19))$. The mean number of doses of surfactant administered was 1.74 per infant and no significant differences were noted between the treated and placebo groups in terms of number of doses or improvement in a: $\mathrm{Po}_{2}$ in response to surfactant.

\section{CHRONIC LUNG DISEASE}

Various measures were used to assess the severity and duration of CLD. Table 4 shows the duration of mechanical ventilation and oxygen treatment, the need for and duration of steroid treatment for established CLD and the duration of hospital stay for both survivors and for infants who died. No significant differences were found between the treated and placebo groups.

\section{MAJOR MORBIDITY}

Table 5 shows the incidence of major morbidities. No significant differences were found between the treated and placebo infants. The incidence of complications attributable to steroids in treated and placebo infants are shown in table 6 . Treated infants had a significantly higher incidence of gastrointestinal haemorrhage than the placebo group. Hypertension and hyperglycaemia were seen more often in treated infants but this difference did not meet significance.

\section{CAUSES OF DEATH}

No significant differences were found between treated and placebo infants in the relative frequencies of the different causes of death (table 7). 
Table 7 Causes of death

\begin{tabular}{lcll}
\hline & $\begin{array}{l}\text { Dexamethasone } \\
(n=31)\end{array}$ & $\begin{array}{l}\text { Placebo } \\
(n=22)\end{array}$ & $\begin{array}{l}\text { Odds ratio } \\
(95 \% \text { CI })\end{array}$ \\
\hline Acute respiratory & $7(23)$ & $6(27)$ & $0 \cdot 78(0 \cdot 22,2 \cdot 74)$ \\
Intraventricular haemorrhage & $10(32)$ & $8(36)$ & $0 \cdot 84(0 \cdot 27,2 \cdot 62)$ \\
Chronic respiratory & $3(10)$ & 0 & $5 \cdot 92(0 \cdot 57,61 \cdot 57)$ \\
Infection & $3(10)$ & $3(14)$ & $0 \cdot 68(0 \cdot 12,3 \cdot 75)$ \\
Congenital anomaly & 0 & 0 & 1 \\
Other & $8(26)$ & $5(23)$ & $1 \cdot 18(0 \cdot 33,4 \cdot 14)$ \\
\hline
\end{tabular}

\section{Discussion}

This study has shown that an early, short postnatal course of dexamethasone does not prevent the development of CLD or reduce mortality in severe RDS. The only significant difference between the groups which may suggest benefit was the improved respiratory status of the treated infants group at 3 days of age. This difference, however, was not sustained at 7 days of life. In addition, this finding did not find expression in a reduction in either incidence or severity of chronic lung disease.

Complications, which were attributable, in the opinion of the attending neonatologist, to steroid treatment, were more common in the treated group. Gastrointestinal haemorrhage was significantly more common in treated infants and there was also a non-significant increase in hypertension and hyperglycaemia. No cases of gastrointestinal perforation were recorded. In spite of the slight increase in hypertension, there was no difference between the groups in the incidence of intracranial haemorrhage. The mean number of doses of dexamethasone administered was 5.5 out of a possible six in both groups and, in total, only 23 infants (9\%) did not receive the complete course of the study drug, suggesting that the severity of the side effects was relatively mild.

Previous reports of the use of early postnatal steroid treatment have provided mixed results. Baden et al $^{14}$ in 1972 were unable to demonstrate any immediate benefit from the administration of two doses of hydrocortisone within the first day of life. No improvement was found in requirement for oxygen or ventilation in the first 72 hours and no difference in mortality was found between treated and untreated infants. In addition, no benefit was seen in the subgroup of infants whose mothers had received antenatal steroids. Yeh et al in $1990^{13}$ demonstrated improved acute respiratory status, increased extubation by 14 days, and less chronic lung disease with a 12 day tapering course of dexamethasone. Treated infants showed a transient decrease in mean airway pressure and sustained improvement in pulmonary compliance. Yeh also noted a trend toward decreased mortality. Hypertension and hyperglycaemia were significantly more common in the dexamethasone group. Sanders et al ${ }^{15}$ studied the effect of two doses of dexamethasone in the first 24-36 hours of life. Treated infants had improved survival, shorter duration of hospital stay, and fewer days of ventilation or oxygen therapy. Two subsequent studies have been reported in abstract form. Yeh et al ${ }^{16}$ reported a multicentre study of early and prolonged (four weeks) dexamethasone administration in which they found a
Table 8 Summary of reported randomised controlled clinical trials of early postnatal steroids in RDS

\begin{tabular}{lllccc}
\hline Author & Year & Steroid & $\begin{array}{l}\text { Duration of } \\
\text { treatment }\end{array}$ & $\begin{array}{l}\text { Steroids } \\
(n)\end{array}$ & $\begin{array}{l}\text { Placebo } \\
(n)\end{array}$ \\
\hline Baden & 1972 & Hydro & 1 Day & 22 & 22 \\
Yeh & 1990 & Dex & 12 Days & 28 & 29 \\
Sanders & 1992 & Dex & 1 Day & 19 & 21 \\
Yeh & 1993 & Dex & 28 Days & 75 & 67 \\
Rastogi & 1993 & Dex & 12 Days & 32 & 32 \\
Present study & 1994 & Dex & 3 Days & 132 & 116
\end{tabular}

Hydro=hydrocortisone; Dex=dexamethasone.

reduction in the incidence of chronic lung disease and lower $\mathrm{PCO}_{2}$ values in treated infants. There were no differences in mortality or acute respiratory status. Rastogi et al ${ }^{17}$ reported a study of the 12 day tapering course of dexamethasone as in Yeh's first study, but in conjunction with surfactant therapy, and found a reduction in chronic lung disease, improved pulmonary function, and no change in mortality.

None of the studies described above was designed with a sample size sufficient to evaluate many of the major complications seen in severe RDS. This study is much larger, thus increasing the statistical power of the results (table 8). However, in view of the conflicting results of the studies, it clearly will be necessary to undertake a much larger trial in order to determine whether a true significant reduction in the incidence of chronic lung disease can be achieved with early postnatal steroid treatment.

Several possible explanations can be proposed for the lack of effect of the three day course of dexamethasone despite the solid theoretical basis for the intervention. The moderate improvement in respiratory status at 72 hours in treated infants which disappeared later may support the hypothesis that a longer course of steroid treatment is required in order to suppress sufficiently the inflammatory response in the lungs and allow the process of recovery to take place. Another possible explanation is that postnatal steroid treatment is in fact not effective and that differences found in smaller trials were not generalisable. Also, it may be that the effect of steroid treatment is masked by the improvement in outcome resulting for surfactant therapy. Only one of the trials reporting a positive effect of steroids included surfactant administration for all infants.

We conclude that the present study does not support the routine use of early postnatal steroid treatment for the prevention of chronic lung disease, but that there is sufficient evidence to justify a much larger multicentre study of early prolonged dexamethasone treatment.

This study was supported by a grant from CTS Industries, Israel. Surfactant TA was kindly supplied by Tokyo Tanabe, Japan.

We thank Mrs C Smith (pharmacist), Mrs C Malka (Study co-ordinator), and Mrs L Frumerman (data analysis) for their immense assistance on this project.

1 AAP Committee on the Fetus and Newborn. Surfactan replacement therapy for respiratory distress syndrome. replacement therapy for

2 Fujiwara T, Konishi M, Chida S, Ogawa Y, Takeuchi Y. Surfactant replacement therapy with a single postventilatory dose of a reconstituted bovine surfactant in preterm 
infants with respiratory distress syndrome: Final analysis of a multicenter, double-blind, randomized trial and comof a multicenter, double-blind, randomized trial and com-

parison with similar trials. Pediatrics 1990; 86: 753-64.
3 Soll RF, McQueen MC. Respiratory distress syndrome. In Effective care of the newborn infant. Oxford: Oxford Effective care of the newborn
University Press, 1992: 325-58.

4 Avery G, Fletcher AB, Kaplan M, Brudno DS. Controlled trial of dexamethasone in respirator-dependent infants with bronchopulmonary dysplasia. Pediatrics 1985; 75: 106-11.

5 Cummings JJ, D'Eugenio DB, Gross SJ. A controlled trial of dexamethasone in preterm infants at risk for bronchopulmonary dysplasia. N Engl f Med 1989; 320: 1505-10.

6 Harkavy KL, Scanlon JW, Chowdhry PK, Grylack LJ. Dexamethasone therapy for chronic lung disease in ventilator- and oxygen-dependent infants: A controlled trial. $\mathcal{f}$ Pediatr 1989; 115: 979-83.

7 Collaborative Dexamethasone Trial Group. Dexamethasone therapy in neonatal chronic lung disease: An international, placebo-controlled trial. Pediatrics 1991; 88 421-7.

8 Merritt TA, Stuard ID, Puccia J, Wood B, Edwards DK Finkelstein J, et al. Newborn tracheal aspirate cytology: classification during respiratory distress syndrome and bronchopulmonary dysplasia. F Pediatr 1981; 98: 949-56.

9 Ogden B, Murphy S, Saunders G, Pathak D, Johnson J. Neonatal lung neutrophils and elastase/proteinase inhibitor imbalance. Am Rev Respir Dis 1984; 130: 817-21.

10 McColm J, McIntosh N. Tracheal IL8 as a predictor of chronic lung disease. Ped Res 1994; 36: A153.

11 Groneck P, Opperman M, Speer CP. Levels of complement anaphylatoxin $\mathrm{C} 5 \mathrm{a}$ in pulmonary effluent fluid of infants an risk for chronic lung disease and effects of dexamethaat risk for chronic lung disease and effects

12 Groneck P, Reuss D, Goetze-Speer B, Speer CP. Effects of dexamethasone on chemotactic activity and inflammator mediators in tracheobronchial aspirates of preterm infants at risk for chronic lung disease. $f$ Pediatr 1993; 122: 938-44.

13 Yeh TF, Torre JA, Rastogi A, Anyebuno MA, Pildes RS. Early postnatal dexamethasone therapy in premature infants with severe respiratory distress syndrome: A double-blind, controlled study. F Pediatr 1990; 117: 273-82.

14 Baden M, Bauer CR, Colle E, Klein G, Taeusch HW, Stern L. A controlled trial of hydrocortisone therapy in infants with respiratory distress syndrome. Pediatrics 1972; 50: 526-34.

15 Sanders RJ, Cox C, Phelps DL, Sinkin RA. Two doses of early intravenous dexamethasone for the prevention of bronchopulmonary dysplasia in babies with respiratory distress syndrome. Ped Res 1994; 36: 122-8.

16 Yeh TF, Lin IJ, Shieh WS, Lin HC, Lin CH, Chen JY, et al. Prevention of chronic lung disease in premature RDS infants with early and prolonged dexamethasone therapy a multicenter, double-blind controlled study. Ped Res 1994; 36: $262 \mathrm{~A}$.

17 Rastogi A, Morales P, Akintorin S, Bez M, David R, Pildes RS. Randomized, double-blind trial of dexamethasone plus surfactant for prevention of bronchopulmonary dysplasia. Ped Res 1994; 36: 1486A

18 Giedion A, Haefliger H, Dangel P. Acute pulmonary x-ray changes in hyaline membrane disease treated with artificial ventilation and positive end-expiratory pressure. Pediatr Radiol 1973; 1: 145-52.

19 Levene MI. Measurement of the growth of the lateral ventricles in preterm infants with real-time ultrasound. ventricles in Dis Child 1981; 56: 900-4.

20 Committee for the classification of ROP. An international classification of retinopathy of prematurity. Pediatrics 1984; 74: 127-33.

21 van Houten J, Long W, Mullett $M$, Finer N, Derleth D, McMurray $\mathrm{B}$, et al. Pulmonary hemorrhage in premature infants after treatment with synthetic surfactant: an autopsy evaluation. F Pediatr 1992; 120: S40-4. 